\title{
Mini-symposium
}

\section{Fetal origins of adult disease: introduction}

\begin{abstract}
$\mathrm{t}$ is becoming clear that, while the number of people dying from heart disease continues to fall each year in countries such as the UK, the number of people suffering from this disease is rising. ${ }^{1}$ In part this is due to the age structure of developed societies, but it also emphasises that we are still far from understanding the causes of heart disease. Until we do, prevention will be difficult. The concept that prenatal and early childhood factors play an important role in this aetiology is now well established ${ }^{2}$ and this theory and its implications are being explored. ${ }^{3}{ }^{4}$

The collection of short reviews in this symposium highlights areas of current research of direct relevance to cardiovascular disease. Mark Hanson and Peter Gluckman examine how their concept of predictive adaptive responses may be applied to vascular endothelial dysfunction, as this plays a key role in the development of vascular and related
\end{abstract}

disease such as metabolic syndrome. Kent Thornburg and Samantha Louey review the evidence that prenatal factors can alter cardiac development in ways which predispose to later disease. Omar Khan and Cliff Shearman enquire whether there may also be a role for early developmental factors in the origins of peripheral vascular disease, an area which has received less attention in this context. Helena Gardiner reviews the effects of changes in load on fetal cardiac development, as processes which determine the limits of compensation underlie possible later failure. Finally, Julian Boullin and John Morgan draw attention to the role of changes in cardiac rhythmogenesis, very little investigated in comparison to hypertension and atherogenesis as components of the developmental origins of heart disease.

Far from providing definite answers, the symposium draws attention to the need for further research, from animal and human physiology to epidemiology, if the insights from the developmental origins of disease concept are to be exploited in terms of cardiovascular disease prevention.

M Hanson

Correspondence to: Professor Mark Hanson, Centre for Developmental Origins of Health and Disease, University of Southampton, Princess Anne Hospital, Southampton, UK: m.hanson@soton.ac.uk

\section{REFERENCES}

1 British Heart Foundation. 2004 Coronary heart disease statistics. www.heartstats.org.

2 Barker DJP. Fetal programming of coronary heart disease. Trends Endocrinol Metab 2002; 13:364-8.

3 Bateson P, Barker D, Clutton-Brock T, et al. Developmental plasticity and human health. Nature 2004;430:419-21.

4 Gluckman PD, Hanson MA. Living with the past: evolution, development and patterns of disease. Science 2004;305:1733-6.

\section{IMAGES IN CARDIOLOGY}

\section{Coronary steal induced by angiogenesis following bypass surgery}

A toutine coronary artery bypass grafting, surgeons chose to resect a left apical bullous discovered as an incidental finding. The patient developed recurrent angina and was investigated by coronary angiography, which was performed six months after his bypass operation.

Selective injection of the left internal mammary artery (LIMA) (arrowhead) was performed by a catheter introduced via the left radial artery. This showed that there were extensive bridging collaterals arising from the LIMA with collateral filling of the left pulmonary artery (arrow). Blood supply to the native left anterior descending artery via the LIMA was presumably compromised by a steal phenomenon into the low pressure pulmonary circulation. This case represents a vivid demonstration of new vessel angiogenesis, from an artery rendered free of side branches at surgical mobilisation, and suggests great potential for this form of treatment in ischaemic heart and peripheral vascular disease. The stimulus to angiogenesis was presumably surgical inflammation of lung and vascular tissue, laid in apposition. It may be best to avoid simultaneous lung resection at the time of LIMA harvest.

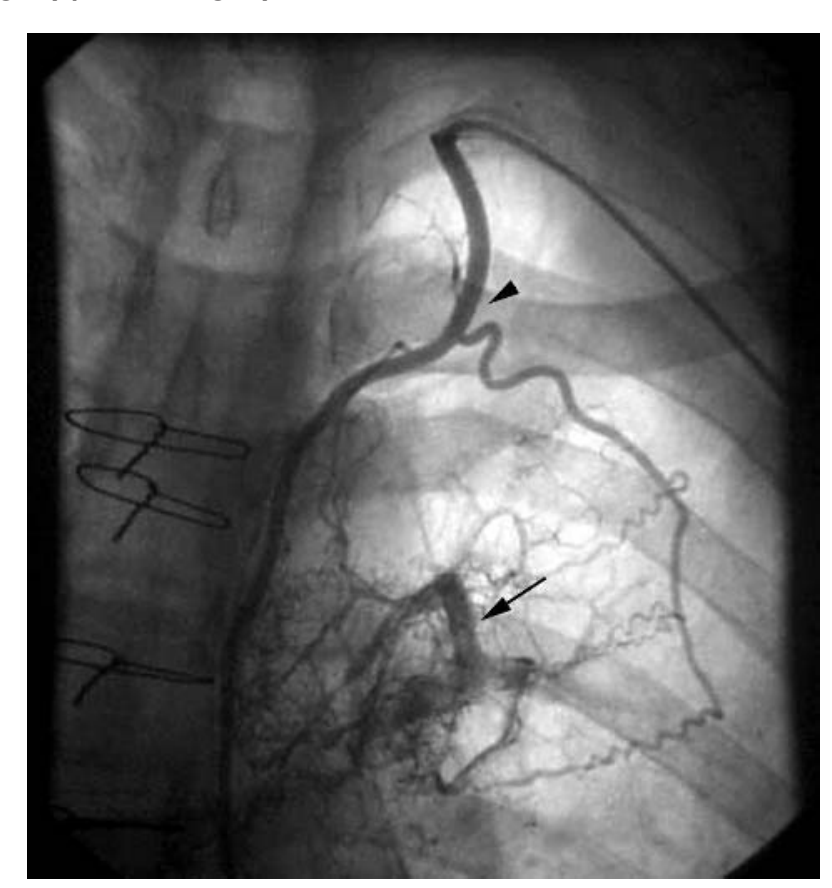

